\title{
Prognostic Factors in Patients with Locally Advanced Breast Cancer Treated by Neoadjuvant Chemotherapy
}

\author{
Min Jaegal, M.D., Shin Jae Kang, M.D., Young Jae Ryu, M.D., Jin Seong Cho, M.D., Min Ho Park, M.D., Ph.D., \\ Jung Han Yoon, M.D., Ph.D. \\ Department of Surgery, Chonnam National University Hwasun Hospital and Medical School, Hwasun, Jeollanam-do, Korea
}

Purpose: Neoadjuvant chemotherapy (NAC) has become the standard treatment for patients with locally advanced breast cancer. The purpose of this study was to evaluate prognosis according to molecular subtype and clinicopathologic factors in patients with locally advanced breast cancer treated by NAC. Methods: We retrospectively analyzed the medical records of 91 patients with breast cancer who underwent NAC followed by surgery between January 2005 and January 2010. The patients were classified into four molecular subtype groups: luminal A, luminal B, HER2 enriched, and triple negative (TN). Results: Thirty-five (38\%) patients had luminal A, 13 (14\%) patients luminal B, 22 (24\%) patients HER2 enriched and 21 (21\%) patients TN breast cancer. Patients with TN breast cancer tended to be more than 50 years of age and to have a higher histologic grade. There were statistically significant differences according to ypN stage (ypN0 vs. ypN1-3; $p=0.019$, 5 -year disease-free survival [DFS]; $p=0.005$, 5-year overall survival [OS]) and lymphovascular invasion (LVI) ( $p=0.003,5$-year DFS; $p=0.006$, 5 -year OS) in the univariate analysis. In the multivariate analysis, LVI was a significant factor in 5-year DFS (odds ratio $2.145,95 \%$ confidence interval 1.064-4.324, $p=0.033)$. There was no significant difference among molecular subtypes in DFS $(p=0.161)$ or OS $(p=0.084)$. Conclusion: LVI was associated with prognosis in patients with locally advanced breast cancer treated by NAC and surgery. However, molecular subtype had no effect on 5-year DFS or OS.

Key Words: Breast neoplasms, Neoadjuvant therapy, Prognosis

\section{INTRODUCTION}

Neoadjuvant chemotherapy (NAC) is increasingly being used for the benefits of tumor downstaging to facilitate breast-conservation therapy, to assess in vivo response to therapy, and to potentially downstage axillary lymph nodes (ALNs) [1-3]. NAC is also widely used in patients with early stage breast cancer. However, not all patients with breast cancer benefit from NAC. There may be identifiable subgroups that benefit more from this treatment than do other subgroups $[4,5]$. Therefore, numerous surrogate endpoints have been investigated in the setting of NAC. Rates of pathologic complete response (pCR) range from $16 \%$ to $20 \%$ according to the histologic subtypes of tumor and treatment modalities. Achievement of pCR has been correlated with better disease-free survival (DFS) and overall survival (OS) [6-8].

Correspondence: Jung Han Yoon, M.D., Ph.D.

Department of Surgery, Chonnam National University Hwasun Hospital and Medical School, 322 Seoyang-ro, Hwasun-eup, Hwasun-gun, Jeollanam-do 58128 , Korea

Tel: +82-61-379-7646, Fax: +82-61-379-7661, E-mail: jhyoon@jnu.ac.kr

Received: Sep 5, 2018 Revised: Oct 16, 2018 Accepted: Apr 13, 2019
Recent studies have used gene expression profiling to classify breast cancers into distinct molecular subgroups and have suggested that this categorization could be used to predict prognosis. In patients treated with NAC, molecular subtype according to gene expression profiling could also effectively identify patients who are likely to achieve pCR [911]. The purpose of our study was to evaluate prognosis according to molecular subtype and clinicopathologic factors in patients with locally advanced breast cancer treated by NAC.

\section{METHODS}

We retrospectively analyzed the medical records of 135 patients with breast cancer who underwent NAC followed by surgery between January 2005 and January 2010. Exclusion criteria were distant metastases at diagnosis or inadequate follow up. In total, 91 patients were enrolled in this study.

All patients underwent core needle biopsy before surgery and surgical resection for breast cancer with sentinel lymph node biopsy (SLNB) and/or ALN dissection after NAC. The anthracycline- and tax- 
ane-based NAC regimens were chosen based on ALN involvement.

After completion of NAC, the patients underwent dynamic contrast-enhanced breast magnetic resonance imaging for measuring tumor size.

Patients were classified into the previously suggested immunohistochemistry (IHC)-based molecular subgroups as follows: luminal A (estrogen receptor [ER]-positive or progesterone [PR]-positive/human epidermal growth factor receptor 2 [HER2]-negative), luminal B (ER-positive or PR-positive/HER2-positive), HER2 enriched (ER-negative and PR-negative/HER2-positive), and triple negative (ER-negative, PR-negative, and HER2-negative). ER, PR, and HER2 were evaluated using standard avidin-biotin complex immunohistochemical staining methods. The ER and PR status was assessed using the Allred score, which was expressed as the sum of the proportion score and the intensity score of positively stained tumor cells. Tumors with an Allred score of at least 3 were regarded as positive. The intensity of HER2 staining was scored as $0,1+, 2+$, or $3+$. Tumors with a $3+$ score were classified as HER2 positive, and tumors with a 0 or $1+$ score were classified as HER2-negative. In tumors with a $2+$ score, gene amplification using silver in situ hybridization was used to identify HER2 status.

After completion of NAC, the size and extent of residual cancer were measured. The pCR was defined as the complete disappearance of invasive carcinoma in the breast and axilla. Residual ductal carcinoma in situ was included in the pCR category. All specimens were reviewed by an experienced pathologist.

Intraoperative subcutaneous injection of diluted indigo-carmine dye in the subareolar area was performed in the same fashion according to the surgeon's standard SLNB practice.

Wilcoxon signed-rank tests, Kruskal-Wallis tests, Mann-Whitney U-tests, Fisher's exact tests, logistic regression, Spearman's correlations, and binary logistic regression analyses were used as appropriate. All variables were subjected to univariate analyses, and then the variables that were associated $(p \leq 0.1)$ were analyzed in a stepwise multivariate logistic regression model. Analyses were performed using the SPSS version 19.0 statistical software package (IBM Corp., Armonk, USA), with $p<0.05$ considered significant.

\section{RESULTS}

This retrospective study included 91 female patients with a median
Table 1. Patients and tumor characteristics

\begin{tabular}{|c|c|}
\hline Characteristic & $\begin{array}{c}\text { Value }(n=91) \\
\text { No. }(\%)\end{array}$ \\
\hline Age at diagnosis (yr)* & $46(27-78)$ \\
\hline BMI $(\mathrm{kg} / \mathrm{m} 2)^{*}$ & $24.0(18.6-31.6)$ \\
\hline \multicolumn{2}{|l|}{ Surgical method } \\
\hline Breast conserving surgery & $32(35.2)$ \\
\hline Mastectomy & $59(64.8)$ \\
\hline \multicolumn{2}{|l|}{ Type of axillary surgery } \\
\hline Sentinel lymph node biopsy & $2(2.2)$ \\
\hline Axillary lymph node dissection & $89(97.8)$ \\
\hline \multicolumn{2}{|l|}{ Tumor histologic type } \\
\hline Invasive ductal or lobular carcinoma & $85(93.4)$ \\
\hline Others & $6(6.6)$ \\
\hline \multicolumn{2}{|l|}{ Clinical T stage } \\
\hline cT1 & $5(5.5)$ \\
\hline cT2 & $22(24.2)$ \\
\hline cT3 & $21(23.0)$ \\
\hline cT4 & $43(47.3)$ \\
\hline \multicolumn{2}{|l|}{ урT stage } \\
\hline T0 & $4(4.4)$ \\
\hline Tis & $4(4.4)$ \\
\hline $\mathrm{T} 1$ & $36(39.5)$ \\
\hline $\mathrm{T} 2$ & $39(42.9)$ \\
\hline $\mathrm{T} 3 / \mathrm{T} 4$ & $8(8.8)$ \\
\hline \multicolumn{2}{|l|}{ ypN stage } \\
\hline No & $31(34.1)$ \\
\hline Nmic/N1 & $28(30.8)$ \\
\hline N2 & $20(22.0)$ \\
\hline N3 & $12(13.2)$ \\
\hline \multicolumn{2}{|l|}{ Estrogen receptor status } \\
\hline Negative & $47(51.6)$ \\
\hline Positive & $44(48.4)$ \\
\hline \multicolumn{2}{|l|}{ Progesterone receptor status } \\
\hline Negative & $54(59.3)$ \\
\hline Positive & $37(40.7)$ \\
\hline \multicolumn{2}{|l|}{ HER2 receptor status } \\
\hline Negative & $56(61.5)$ \\
\hline Positive & $35(38.5)$ \\
\hline \multicolumn{2}{|l|}{ Lymphovascular invasion } \\
\hline Negative & $54(60.0)$ \\
\hline Positive & $37(40.0)$ \\
\hline \multicolumn{2}{|l|}{ Neoadjuvant chemotherapy } \\
\hline Taxane based & $87(95.6)$ \\
\hline Non-taxane & $4(4.4)$ \\
\hline \multicolumn{2}{|l|}{ Radiation therapy } \\
\hline Yes & $75(82.4)$ \\
\hline No & $16(17.6)$ \\
\hline \multicolumn{2}{|l|}{ Hormonal therapy } \\
\hline Yes & $43(47.3)$ \\
\hline No & $48(52.7)$ \\
\hline \multicolumn{2}{|l|}{ Trastuzumab therapy } \\
\hline Yes & $16(17.6)$ \\
\hline No & $75(82.4)$ \\
\hline
\end{tabular}

Results are shown as $n$ (\%) unless indicated otherwise. $\mathrm{BMI}=$ body mass index; Nmic = node micrometastasis; HER2 = human epidermal growth factor receptor 2 .

*median (range). 
age of 46 (27-78) years. Their mean body mass index was $24.0 \mathrm{~kg} / \mathrm{m}^{2}$. A total of 59 patients (64.8\%) underwent mastectomy, 89 patients (97.8\%) underwent ALN dissection, 85 patients (93.4\%) had invasive ductal or lobular carcinoma, and 43 patients (47.3\%) were at clinical stage T4. The pCR rate was $8.8 \%$ (8 patients); however, 31 patients (34.1\%) had stage ypN0 disease. The number of patients with positive ER, PR, and HER2 status were 44 (48.4\%), 37 (40.7\%) and 35 (38.5\%), respectively. Lymphovascular invasion (LVI) was observed in 36 patients (40.0\%), 87 patients (95.6\%) were treated with taxane based NAC, 75 patients (82.4\%) underwent radiation therapy, 43 patients (47.3\%) underwent hormonal therapy, and 16 patients (17.6\%) underwent trastuzumab therapy (Table 1).

Thirty five patients had luminal A, 13 had luminal B, 22 had HER2 enriched, and 21 had triple negative (TN) breast cancer. Most of the

Table 2. Initial clinical stage according to tumor subtype

\begin{tabular}{lccccc}
\hline \multirow{2}{*}{ Clinical stage } & \multicolumn{4}{c}{ Tumor subtype } & TN \\
\cline { 2 - 5 } & Luminal A & Luminal B & HER 2 positive & 0 & $3(3.3)$ \\
2A & 3 & 0 & 0 & 1 & $2(2.2)$ \\
2B & 0 & 1 & 0 & 9 & $32(35.2)$ \\
3A & 12 & 3 & 8 & 8 & $36(39.6)$ \\
3B & 18 & 4 & 6 & 3 & $18(19.7)$ \\
3C & 2 & 5 & 22 & 21 & 91 \\
Total & 35 & 13 & 8 & & \\
\hline
\end{tabular}

$\mathrm{TN}=$ triple negative; HER2 = human epidermal growth factor receptor 2.

Table 3. Clinicopathological characteristics according to tumor subtype

\begin{tabular}{|c|c|c|c|c|c|}
\hline \multirow[b]{2}{*}{ Variables } & \multicolumn{4}{|c|}{ Tumor subtype } & \multirow[b]{2}{*}{$p$-value } \\
\hline & $\begin{array}{l}\text { Luminal A } \\
\qquad(n=35) \\
\text { No. }(\%)\end{array}$ & $\begin{array}{l}\text { Luminal B } \\
\qquad(n=13) \\
\text { No. }(\%)\end{array}$ & $\begin{array}{l}\text { HER2 positive (\%) } \\
(\mathrm{n}=22) \\
\text { No. }(\%)\end{array}$ & $\begin{array}{c}\text { TN } \\
(n=21) \\
\text { No. }(\%)\end{array}$ & \\
\hline Age (yr) & & & & & $<0.001$ \\
\hline$<50$ & $32(91.4)$ & $5(38.5)$ & $10(45.5)$ & $10(47.6)$ & \\
\hline$\geq 50$ & $3(8.6)$ & $8(61.5)$ & $12(54.5)$ & $11(52.4)$ & \\
\hline Laterality & & & & & 0.612 \\
\hline Right & $20(57.1)$ & $9(69.2)$ & $11(50.0)$ & $10(47.6)$ & \\
\hline Left & $15(42.9)$ & $4(30.8)$ & $11(50.0)$ & $11(52.4)$ & \\
\hline Clinical T stage & & & & & 0.974 \\
\hline cT1-2 & 10 (28.6) & $4(30.8)$ & $6(27.3)$ & $7(33.3)$ & \\
\hline cT3-4 & 25 (71.4) & $9(69.2)$ & $16(72.7)$ & $14(66.7$ & \\
\hline Surgery & & & & & 0.253 \\
\hline BCS & $16(45.7)$ & $2(15.4)$ & $7(31.8)$ & $7(33.3)$ & \\
\hline Mastectomy & $19(54.3)$ & $11(84.6)$ & $15(68.2)$ & $14(66.7)$ & \\
\hline ypT stage & & & & & 0.591 \\
\hline ypT0, Tis & $3(8.6)$ & 0 & $3(13.6)$ & $2(9.5)$ & \\
\hline урт1-4 & 32 (91.4) & $13(100)$ & $19(86.4)$ & $19(90.5)$ & \\
\hline ypN stage & & & & & 0.150 \\
\hline ypNO & $11(31.4)$ & $2(15.4)$ & $7(31.8)$ & $11(52.4)$ & \\
\hline ypN1-3 & 24 (68.6) & $11(84.6)$ & $15(68.2)$ & $10(47.6)$ & \\
\hline Histologic grade & & & & & 0.040 \\
\hline I & $8(23.5)$ & $1(7.7)$ & $2(10.6)$ & $1(4.8)$ & \\
\hline II & $20(58.8)$ & $5(38.5)$ & $7(36.8)$ & $8(38.1)$ & \\
\hline III & $7(17.7)$ & $7(53.8)$ & $13(52.6)$ & $12(57.1)$ & \\
\hline LVI & & & & & 0.067 \\
\hline No & 17 (48.6) & $6(46.2)$ & $14(66.7)$ & $17(81.0)$ & \\
\hline Yes & $18(51.4)$ & $7(53.8)$ & $8(33.3)$ & $4(19.0)$ & \\
\hline
\end{tabular}

$\mathrm{BCS}=$ breast conserving surgery; $\mathrm{TN}=$ triple negative; HER2 = human epidermal growth factor receptor 2 . 
patients were in clinical stage 3 , and 36 patients $(39.6 \%)$ were in clinical stage 3B (Table 2). Patients with luminal A cancer tended to be less than 50 years of age $(p<0.001)$ and had a middle histologic grade $(p=0.04)$. Patients with luminal B, HER2-positive, and TN cancer tended to be more than 50 years of age $(p<0.001)$ and had a high histologic grade $(p=0.04)$. There was no statistically significant difference in laterality $(p=0.612)$, clinical T stage ( $p=0.974)$, surgical method $(p=0.253)$, ypT stage $(p=0.591)$, ypN stage $(p=0.15)$, or LVI $(p=0.067)$ according to molecular subtype (Table 3$)$. In this study, 6 patients showed pCR and patients with a high histologic grade tended to show pCR, but there was no statistical relation between pCR and other clinical factors such as; age, clinical stage, molecular subtype, LVI, recurrence, or death (Table 4).

There were significant differences in 5-year DFS according to ypN stage (ypN0 vs. ypN1-3; $p=0.019$ ) and LVI (no vs. yes; $p=0.003$ ) in the univariate analysis. In the multivariate analysis, LVI was a significant factor in 5-year DFS (odds ratio 2.145, 95\% confidence interval 1.064$4.324, p=0.033)$ (Table 5). There was a significant difference in 5-year

Table 4. Patients characteristics with pathologic complete response

\begin{tabular}{lcccccc}
\hline Age $(\mathrm{yr})$ & Clinical stage & Molecular subtype & Histologic grade & LVI & Recurrence & Death \\
\hline 44 & IIIB & TN & III & No & No & No \\
47 & IIIA & HER2 $(+)$ & Unknown & No & No & No \\
46 & IIB & Luminal A & III & No & No & No \\
66 & IIIC & HER2 $(+)$ & II & No & No & No \\
57 & IIIC & TN & II & No & Yes & Yes \\
70 & IIIC & HER2 (+) & II &
\end{tabular}

$\mathrm{LVI}=$ lymphovascular invasion; TN = triple negative; HER2 = human epidermal growth factor receptor 2.

Table 5. Univariate and multivariate analysis of prognostic factors for disease-free survival

\begin{tabular}{|c|c|c|c|c|}
\hline \multirow{2}{*}{ Variables } & \multicolumn{2}{|c|}{ Univariate } & \multicolumn{2}{|c|}{ Multivariate } \\
\hline & 5-year DFS (\%) & $p$-value & $\mathrm{RR}(95 \% \mathrm{Cl})$ & $p$-value \\
\hline Age $(<50 / \geq 50$ years $)$ & $53.0 / 71.0$ & 0.162 & & \\
\hline Surgery (BCS/mastectomy) & $62.8 / 57.8$ & 0.472 & & \\
\hline cT stage (cT1-2/T3-4) & $60.5 / 58.9$ & 0.439 & & \\
\hline ypT stage (ypT0/Tis/T1-4) & $68.6 / 58.8$ & 0.552 & & \\
\hline ypN stage (ypN0/N1-3) & $77.5 / 50.5$ & 0.019 & $1.745(0.75-4.058)$ & 0.196 \\
\hline LVI (no/yes) & $71.3 / 40.5$ & 0.003 & $2.145(1.064-4.324)$ & 0.033 \\
\hline Histologic grade (low/high) & $61.4 / 59.8$ & 0.786 & & \\
\hline Radiation therapy (no/yes) & $74.5 / 56.1$ & 0.162 & & \\
\hline Hormone therapy (no/yes) & $64.2 / 54.9$ & 0.877 & & \\
\hline
\end{tabular}

$\mathrm{BCS}=$ breast conserving surgery; $\mathrm{RR}=$ risk ratio; $\mathrm{LVI}=$ lymphovascular invasion .

Table 6. Univariate and multivariate analysis of prognostic factors for overall survival

\begin{tabular}{|c|c|c|c|c|}
\hline \multirow{2}{*}{ Variables } & \multicolumn{2}{|c|}{ Univariate } & \multicolumn{2}{|c|}{ Multivariate } \\
\hline & 5-year OS (\%) & $p$-value & $\mathrm{RR}(95 \% \mathrm{Cl})$ & $p$-value \\
\hline Age $(<50 / \geq 50$ years $)$ & $80.4 / 83.2$ & 0.544 & & \\
\hline Surgery (BCS/mastectomy) & $88.1 / 78.4$ & 0.133 & & \\
\hline cT stage (cT1-2/T3-4) & $86.7 / 79.5$ & 0.496 & & \\
\hline ypT stage (ypT0/Tis/T1-4) & $66.7 / 82.7$ & 0.769 & & \\
\hline ypN stage (ypNo/N1-3) & $96.2 / 74.2$ & 0.005 & 3.491 (0.936-13.028) & 0.063 \\
\hline LVI (no/yes) & $91.6 / 65.7$ & 0.006 & $2.193(0.875-5.497)$ & 0.094 \\
\hline Histologic grade (low/high) & $78.8 / 82.2$ & 0.789 & & \\
\hline Radiation therapy (no/yes) & $87.1 / 80.2$ & 0.781 & & \\
\hline Hormone therapy (no/yes) & $78.8 / 84.5$ & 0.866 & & \\
\hline
\end{tabular}

$\mathrm{BCS}=$ breast conserving surgery; $\mathrm{RR}=$ risk ratio; $\mathrm{LVI}=$ lymphovascular invasion . 
DFS

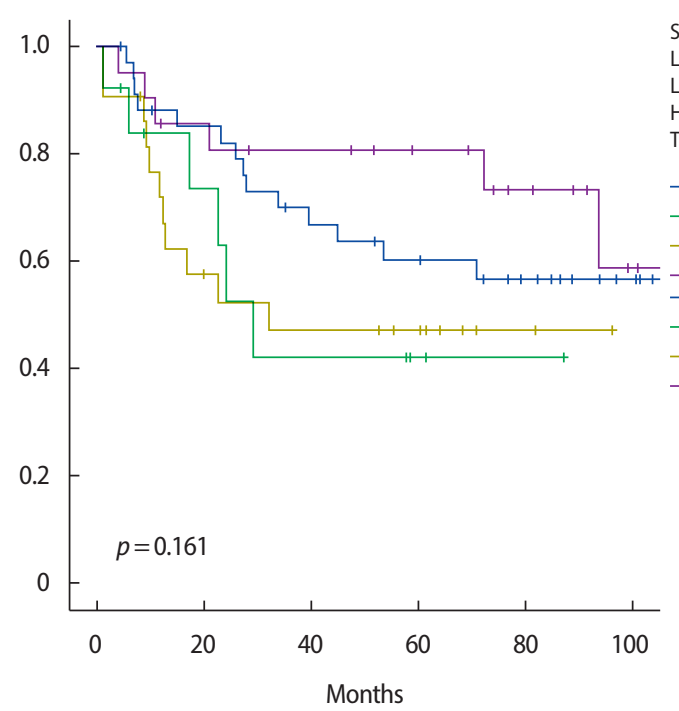

OS

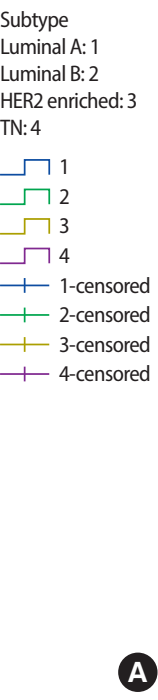

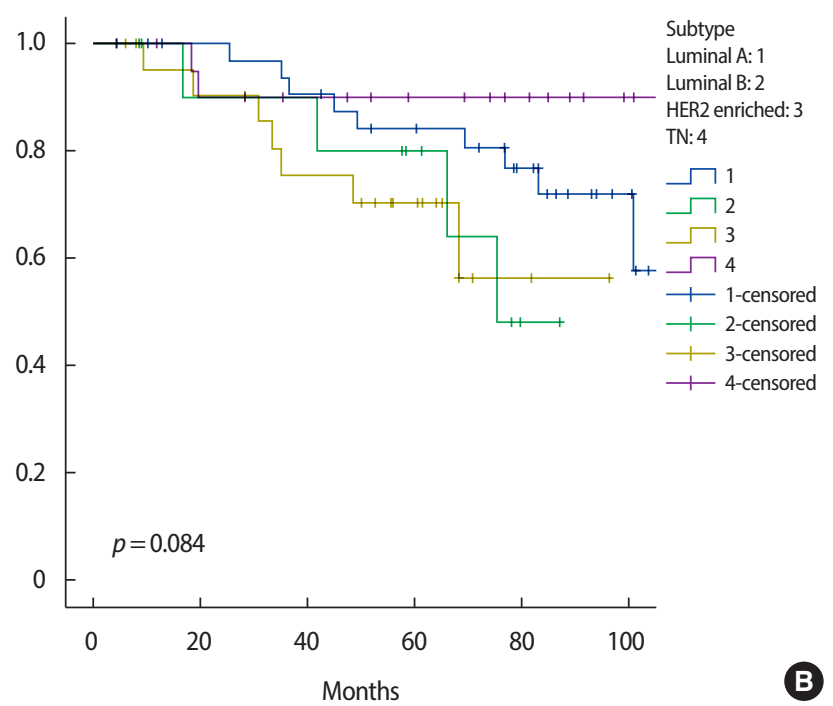

Figure 1. (A) Disease-free survival (DFS) according to tumor subtype. (B) Overall survival (OS) according to tumor subtype.

OS according to ypN stage (ypN0 vs. ypN1-3; $p=0.005$ ) and LVI (no vs. yes; $p=0.006$ ) (Table 6). Molecular subtype was not a significant factor in 5-year DFS or 5-year OS, for which histologic grade had no meaning. We found no significant difference between molecular subtypes in 5-year DFS ( $p=0.161)$ (Figure 1A) or 5-year OS $(p=0.084)$ (Figure 1B).

\section{DISCUSSION}

Few studies have reported differences in tumor cellularity and treatment response patterns of four breast cancer molecular subtypes. Intrinsic differences between the histopathologic characteristics of these subtypes were confirmed in our study. Molecular classification based on gene expression profiling has led to a better understanding of the biological phenotypes of breast cancer $[9,12]$. This is useful in predicting chemo sensitivity as well as prognosis. However, the technical complexity and high costs of this procedure have limited its clinical application. Thus, a combination of immunohistochemical profiles (ER, PR, and HER2) has been investigated as a substitute for the molecular subtypes using gene-expression profiles, although these do not exactly correspond. In this study, we found that the IHC-based molecular subtypes effectively stratified breast cancer for predicting the likelihood of pCR to NAC.

Among the four IHC-based molecular subtypes, patients with the luminal A type (that is, hormone receptor-positive) breast cancer were less likely to achieve pCR [9]. A recent randomized phase II trial showed that neoadjuvant endocrine therapy is effective in ER-positive tumors, producing similar pCR rates as NAC, and better tolerability than NAC [13]. Therefore, neoadjuvant endocrine therapy may be a promising alternative strategy in luminal A breast cancer. In patients with HER2-positive cancer, recent phase III studies have shown that pCR rates were significantly improved with the addition of trastuzumab to conventional chemotherapy [14]. We also found that in patients with HER2-positive tumors, the pCR rate for the trastuzumabtreated group, was nearly twice that for the non-trastuzumab-treated group $[15,16]$. The differences between the two groups were statistically significant after adjustment for confounding factors. Taking these results together, we believe that trastuzumab should be incorporated into NAC for HER2-positive breast cancer. In patients with the TN subtype, because the prognosis of those who failed to achieve PCR is very poor, achieving the highest possible pCR may be particularly important. Therefore, increasing the efficacy of NAC by adding new drugs, such as platinum or poly ADP ribose polymerase inhibitors, might be required to improve the survival of this subgroup [17].

Several studies have reported the association of ALN status and the pathologic primary tumor response to NAC. In previous studies, the response rate of primary breast tumors was correlated with that of the lymph nodes, which were well correlated with DFS [18-20]. However, 
tumor size, histological grade, and HER2 status were not correlated with patient outcome. In the study of Rouzier et al. [21], high histologic grade and a greater than $50 \%$ response to chemotherapy were associated with negative conversion of ALN after NAC. Our results also showed that a high histologic grade and a better response of the primary breast tumor were associated with negative conversion of ALN (Table 6).

There are several limitations in our study. First, this was a retrospective study from a single center and the total number of patients was relatively small. A larger multicenter study with more patients is needed to validate our results. Second, we did not evaluate the recurrence of ALN after surgery because of the relatively short duration of follow-up. A follow-up study of ALN recurrence is needed for better understanding of cancer biology after NAC.

LVI was associated with DFS in patients with locally advanced breast cancer treated by NAC and surgery. However, molecular subtype had no effect on 5-year DFS or OS.

\section{CONFLICT OF INTEREST}

The authors declare that they have no competing interests.

\section{REFERENCES}

1. Kuerer HM, Newman LA, Smith TL, Ames FC, Hunt KK, Dhingra $\mathrm{K}$, et al. Clinical course of breast cancer patients with complete pathologic primary tumor and axillary lymph node response to doxorubicin-based neoadjuvant chemotherapy. J Clin Oncol 1999; $17: 460-9$

2. Charfare H, Limongelli S, Purushotham AD. Neoadjuvant chemotherapy in breast cancer. Br J Surg 2005;92:14-23.

3. Boughey JC, Suman VJ, Mittendorf EA, Ahrendt GM, Wilke LG, Taback B, et al. Sentinel lymph node surgery after neoadjuvant chemotherapy in patients with node-positive breast cancer: the ACOSOG Z1071 (Alliance) clinical trial. JAMA 2013;310:1455-61.

4. Von Minckwitz G, Untch M, Blohmer JU, Costa SD, Eidtmann H, Fasching PA, et al. Definition and impact of pathologic complete response on prognosis after neoadjuvant chemotherapy in various intrinsic breast cancer subtypes. J Clin Oncol 2012;30:1796-804.

5. Denkert C, Loibl S, Noske A, Roller M, Muller B, Komor M, et al.
Tumor-associated lymphocytes as an independent predictor of response to neoadjuvant chemotherapy in breast cancer. J Clin Oncol 2010;28:105-13.

6. Moon T, Cho DH, Youn JM, Lee JB, Bae JW, Jung SP. Evaluation of prognostic factors and validation of tumor response ratios after neoadjuvant chemotherapy in patients with breast cancer. J Breast Dis 2016;4:108-15.

7. Cortazar P, Zhang L, Untch M, Mehta K, Costantino JP, Wolmark N, et al. Pathological complete response and long-term clinical benefit in breast cancer: the CTNeoBC pooled analysis. Lancet 2014;384: $164-72$.

8. Gianni L, Pienkowski T, Im YH, Tseng LM, Liu MC, Lluch A, et al. 5 -year analysis of neoadjuvant pertuzumab and trastuzumab in patients with locally advanced, inflammatory, or early-stage HER2-positive breast cancer (NeoSphere): a multicentre, openlabel, phase 2 randomised trial. Lancet Oncol 2016;17:791-800.

9. Hwang SH, Choi HS, Kim YG, Kim JH, Seong MK, Jang WI, et al. The molecular subtype dependent effect of concurrent radiotherapy and systemic therapy on breast cancer: analysis of a human in vivo model of metastatic brain lesions. J Breast Dis 2016;4: 85-91.

10. Liedtke C, Mazouni C, Hess KR, André F, Tordai A, Mejia JA, et al. Response to neoadjuvant therapy and long-term survival in patients with triple-negative breast cancer. J Clin Oncol 2008;26:1275-81.

11. Feldman LD, Hortobagyi GN, Buzdar AU, Ames FC, Blumenschein GR. Pathological assessment of response to induction chemotherapy in breast cancer. Cancer Res 1986;46:2578-81.

12. Rouzier R, Perou CM, Symmans WF, Ibrahim N, Cristofanilli M, Anderson K, et al. Breast cancer molecular subtypes respond differently to preoperative chemotherapy. Clin Cancer Res 2005;11: 5678-85.

13. Baselga J, Gelmon KA, Verma S, Wardley A, Conte P, Miles D, et al. Phase II trial of pertuzumab and trastuzumab in patients with human epidermal growth factor receptor 2-positive metastatic breast cancer that progressed during prior trastuzumab therapy. J Clin Oncol 2010;28:1138-44

14. Rossari JR, Metzger-Filho O, Paesmans M, Saini KS, Gennari A, Azambuja Ed, et al. Bevacizumab and breast cancer: a meta-analysis of first-line phase III studies and a critical reappraisal of available evidence. J Oncol 2012;2012:8.

15. Untch M, Rezai M, Loibl S, Fasching PA, Huober J, Tesch H, et al. 
Neoadjuvant treatment with trastuzumab in HER2-positive breast cancer: results from the GeparQuattro study. J Clin Oncol 2010; 28:2024-31.

16. Kim MM, Allen P, Gonzalez-Angulo AM, Woodward WA, MericBernstam F, Buzdar AU, et al. Pathologic complete response to neoadjuvant chemotherapy with trastuzumab predicts for improved survival in women with HER2-overexpressing breast cancer. Ann Oncol 2013;24:1999-2004.

17. Lord CJ, Ashworth A. Targeted therapy for cancer using PARP inhibitors. Curr Opin Pharmacol 2008;8:363-9.

18. Sakakibara M, Nagashima T, Kadowaki M, Onai Y, Fujimori T, Yokomizo J, et al. Clinical significance of axillary microresiduals after neoadjuvant chemotherapy in breast cancer patients with cyto- logically proven metastases. Ann Surg Oncol 2009;16:2470-8.

19. Yanagawa M, Ikemot K, Kawauchi S, Furuya T, Yamamoto S, Oka M, et al. Luminal A and luminal B (HER2 negative) subtypes of breast cancer consist of a mixture of tumors with different genotype. BMC Res Notes 2012;5:376.

20. Van De Vijver MJ, He YD, Van't Veer LJ, Dai H, Hart AA, Voskuil DW, et al. A gene-expression signature as a predictor of survival in breast cancer. N Engl J Med 2002;347:1999-2009.

21. Rouzier R, Extra JM, Klijanienko J, Falcou MC, Asselain B, VincentSalomon A, et al. Incidence and prognostic significance of complete axillary downstaging after primary chemotherapy in breast cancer patients with T1 to T3 tumors and cytologically proven axillary metastatic lymph nodes. J Clin Oncol 2002;20:1304-10. 